\title{
Weather forecast in north-western Greece: RISKMED warnings and verification of MM5 model
}

\author{
A. Bartzokas ${ }^{1}$, V. Kotroni ${ }^{2}$, K. Lagouvardos ${ }^{2}$, C. J. Lolis ${ }^{1}$, A. Gkikas ${ }^{1}$, and M. I. Tsirogianni ${ }^{1}$ \\ ${ }^{1}$ Laboratory of Meteorology, Department of Physics, University of Ioannina, Ioannina, Greece \\ ${ }^{2}$ Institute of Environmental Research, National Observatory of Athens, Athens, Greece
}

Received: 17 June 2009 - Revised: 3 February 2010 - Accepted: 9 February 2010 - Published: 25 February 2010

\begin{abstract}
The meteorological model MM5 is applied operationally for the area of north-western Greece for one-year period (1 June 2007-31 May 2008). The model output is used for daily weather forecasting over the area. An early warning system is developed, by dividing the study area in 16 sub-regions and defining specific thresholds for issuing alerts for adverse weather phenomena. The verification of the model is carried out by comparing the model results with observations from three automatic meteorological stations. For air temperature and wind speed, correlation coefficients and biases are calculated, revealing that there is a significant overestimation of the early morning air temperature. For precipitation amount, yes/no contingency tables are constructed for 4 specific thresholds and some categorical statistics are applied, showing that the prediction of precipitation in the area under study is generally satisfactory. Finally, the thunderstorm warnings issued by the system are verified against the observed lightning activity.
\end{abstract}

\section{Introduction}

The area of north-western (NW) Greece presents significant interest from a meteorological point of view, as it often experiences severe weather events. This is due to its geographical position and the influence of its specific morphological characteristics on atmospheric circulation. It mainly consists of the Region of Epirus (the NW part of continental Greece), which is morphologically separated from the eastern part of the country by the Pindus mountain range, orientated from NW to SE and exceeding $2000 \mathrm{~m}$ height. At the NW part of the country, the northern Ionian Sea and the islands of Corfu (Kerkyra) and Paxi usually experience similar weather events (Fig. 1).

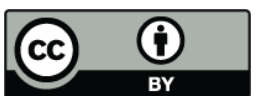

Correspondence to: A. Bartzokas (abartzok@uoi.gr)
During the cold period of the year, weather in NW Greece is affected by Mediterranean depressions, which mainly form in the cyclogenesis regions along the northern Mediterranean coasts and move eastwards over the warm Mediterranean waters towards the southern Balkans (see e.g. Alpert et al., 1990; Maheras et al., 2001; Trigo et al., 2002). Since most of the low pressure systems moving in the Ionian Sea encounter, at first, NW Greece, Epirus is frequently called "the gate of the cyclones to Greece". During the eastwards evolution of these depressions, the surface and upper air flows over NW Greece are usually southerly or southwesterly. The contact with the warm Mediterranean sea-surface makes lowlevel air masses warm and humid, increasing static and potential instability. The high static instability over the sea and the ascending of the potentially unstable air masses on the windward slopes of the Pindus Mountains, along with the positive vorticity advection in the middle troposphere, favour the development of severe precipitation events and thunderstorms. Also, southerly winds over the Ionian Sea and strong easterly downslope flow sometimes occurring in the leeward slopes of the Pindus mountain range can be very strong causing significant problems in human activities (Koletsis et al., 2009).

During the warm period of the year, weather in NW Greece is mainly affected by anticyclonic circulation. The warm and dry subtropical air masses, along with the high static stability over the relatively cool Mediterranean seasurface do not favor the formation and the development of frontal depressions (see e.g. Lolis et al., 2008). The low large-scale sea-level pressure gradient, along with the intense land heating during the day, lead to the formation of local circulations (breezes) and the air mass transfer between land and sea areas. Some times, cold air masses, transferred from northern Europe, prevail in the middle troposphere, instead of the subtropical ones, and these types of circulation along with the high static instability over the land, may lead to the appearance of severe thunderstorms during the afternoon (see e.g. Metaxas, 1978; Dalezios and Papamanolis, 1991;

Published by Copernicus Publications on behalf of the European Geosciences Union. 
(a)

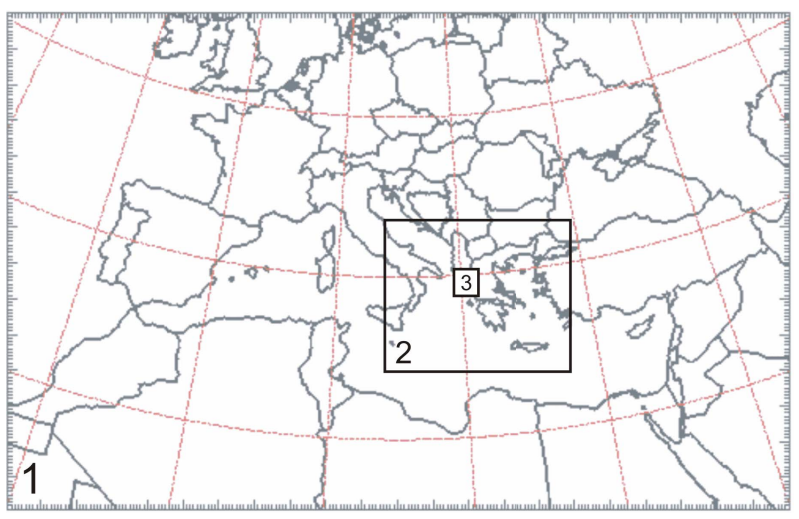

(b)

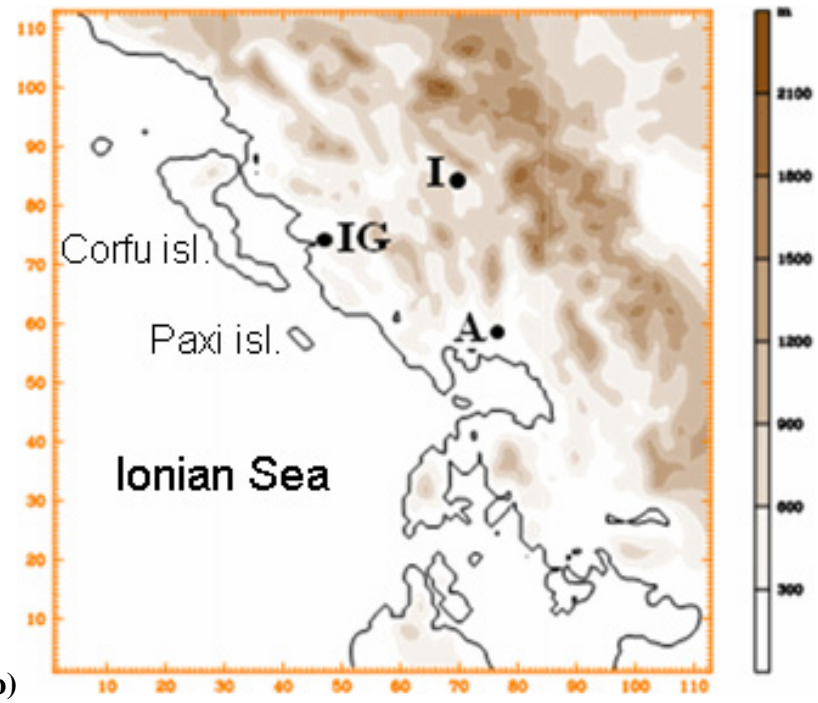

Fig. 1. Representation of (a) the three nested domains used and (b) the model Grid 3 topography (the dots indicate the location of the three surface stations: I - Ioannina, IG - Igoumenitsa, and A Arta).

Kotroni et al., 1997). These thunderstorms may be responsible for significant damages in infrastructure and may become dangerous even for human life.

Severe weather events in NW Greece have been studied by many researchers in the past (see e.g. Bartzokas and Houssos, 2005; Houssos and Bartzokas, 2006; Koletsis et al., 2009), but the attention has been mainly focused on the climatology of these events and not on the analysis and evaluation of high-resolution weather forecasts. By taking into account the aforementioned meteorological, geographical and morphological characteristics of NW Greece, the usage of a meteorological model at high-resolution would be useful, in order to simulate and forecast the significant local circulations and processes that take place over this region. Indeed, Kotroni and Lagouvardos (2004) who verified MM5 nearsurface temperature and wind forecasts over a period of one year over the Greater Area of Athens, Greece, have shown that increasing the grid spacing from 8 to $2 \mathrm{~km}$, results in an improvement of the forecast skill. Therefore, the MM5 meteorological model has been operationally implemented for the area of NW Greece at a high resolution $(2 \times 2 \mathrm{~km}$ grid $)$. The operational weather forecast chain was performed on daily basis from 1 June 2007 to 31 May 2008 as a part of RISKMED project (Bartzokas et al., 2010), which was financed by the EU and the Ministry of Economy of Greece in the frame of INTERREG IIIB/ARCHIMED programme. MM5 model outputs are used for issuing warnings in 16 subregions defined over the area of Epirus. In order to examine the accuracy of the model outputs and of the corresponding warnings, a verification procedure is carried out, by using surface meteorological observations. This verification is completed through the use of lightning data, in order to assess the model ability to predict thunderstorm activity.

\section{Data and methodology of verification}

\subsection{MM5 model}

The MM5 model (version 3.6) is a non-hydrostatic model, which has been widely used by many institutes and meteorological services around the world (Dudhia, 1993). MM5 allows the selection among a large number of parameterization schemes of various physical processes. In the present study, the microphysical scheme described by Schultz (1995) and the convective parameterization scheme of Kain and Fritsch (1993) are selected. After testing the implementation of many schemes, this selection has been found to be the best for the Greek area (Kotroni and Lagouvardos, 2001). For the atmospheric boundary layer, the scheme of Hong and Pan (1996), known as MRF scheme, is used. The selection of MRF scheme is based on the findings by Akylas et al. (2007), who have compared the MM5 operational forecasts over Athens with three different atmospheric boundary layer schemes for the warm period of 2002. They found that the MRF scheme produced the best forecasts in terms of near-surface temperature.

Weather forecasts are performed on a daily basis, using the following 1-way nesting strategy (Fig. 1): Grid 1 (24$\mathrm{km}$ horizontal grid increment) covers the major part of Europe and the Mediterranean, Grid 2 (8-km horizontal grid increment) covers Greece and the surrounding waters, while Grid 3 (2-km horizontal grid increment) covers Epirus area and part of the Ionian Sea. The 00:00 UTC Global Forecast System (GFS, provided by the National Centers for Environmental Predictions-NCEP, USA) gridded analysis fields and 6-h interval forecasts, at 1-degree lat/lon resolution, are used to initialize the model and to nudge the boundaries of Grid 1 during the simulation period. Grid 1 and 2 simulations last for $72 \mathrm{~h}$ and Grid 3 for $48 \mathrm{~h}$. 


\subsection{Observational data}

For the verification procedure, meteorological data from three automatic weather stations operating in the areas of the towns Ioannina, Arta and Igoumenitsa are used. The location of the three stations is shown in Fig. 1b. Moreover, for the verification of thunderstorm forecasts and to compensate the scarcity of weather stations, especially in the mountainous areas, data from the lightning detection system ZEUS, operated by the National Observatory of Athens are used. Details on ZEUS system, its detection efficiency and location errors are given in Kotroni and Lagouvardos (2008) and Lagouvardos et al. (2009).

\subsection{Verification methodology}

The MM5 outputs at the grid points that are closest to the three meteorological stations are used for the model verification. For air temperature, the verification is carried out for the $t+4, t+12, t+28$ and $t+36-h$ forecast outputs of the model Grid 3. These outputs are compared with the observations at 04:00 and 12:00 UTC (Greek local time is UTC+2 during winter and UTC+3 during summer). 04:00 UTC and 12:00 UTC have been selected, by taking into account that the air temperature approaches the daily minimum and maximum values, respectively, at these times of the day. For wind speed, the verification is carried out for $t+12$ and $t+36$ only, since, very early in the morning, in most cases, the wind speed is very low. For precipitation, the verification refers to the forecast of the total daily amount (24-h accumulated precipitation, starting at 00:00 UTC), as well as to the four 6hourly forecasts of the day. These amounts are calculated by averaging the 24-h and 6-h forecast values of the six neighboring grid points around the corresponding station. A $2 \times 2$ (yes/no) contingency table is then constructed for each station and for each of the precipitation thresholds $(2,8,15$, and $30 \mathrm{~mm}$ ). Categorical statistics are computed in order to describe particular aspects of precipitation forecast performance. Specifically, accuracy (AC), bias score (BIAS), probability of detection (POD), false alarm ratio (FAR), probability of false detection (POFD), threat score (CSI), equitable threat score (ETS), Hanssen and Kuipers discriminant (HK), Heidke skill score (HSS) and Odds ratio (OR) are calculated. AC expresses the fraction of the correct forecasts. BIAS measures the ratio of the frequency of forecast events to the frequency of observed events and it indicates whether the forecast system has a tendency to underpredict $(\mathrm{BIAS}<1$ ) or overpredict (BIAS $>1$ ) events. POD expresses the fraction of the observed "yes" events that were correctly forecasted. FAR expresses the fraction of the predicted "yes" events that actually did not occur. POFD expresses the fraction of the observed "no" events that were incorrectly forecasted as "yes". CSI measures the fraction of observed and/or forecasted events that were correctly predicted. ETS measures the fraction of observed and/or forecasted events that were

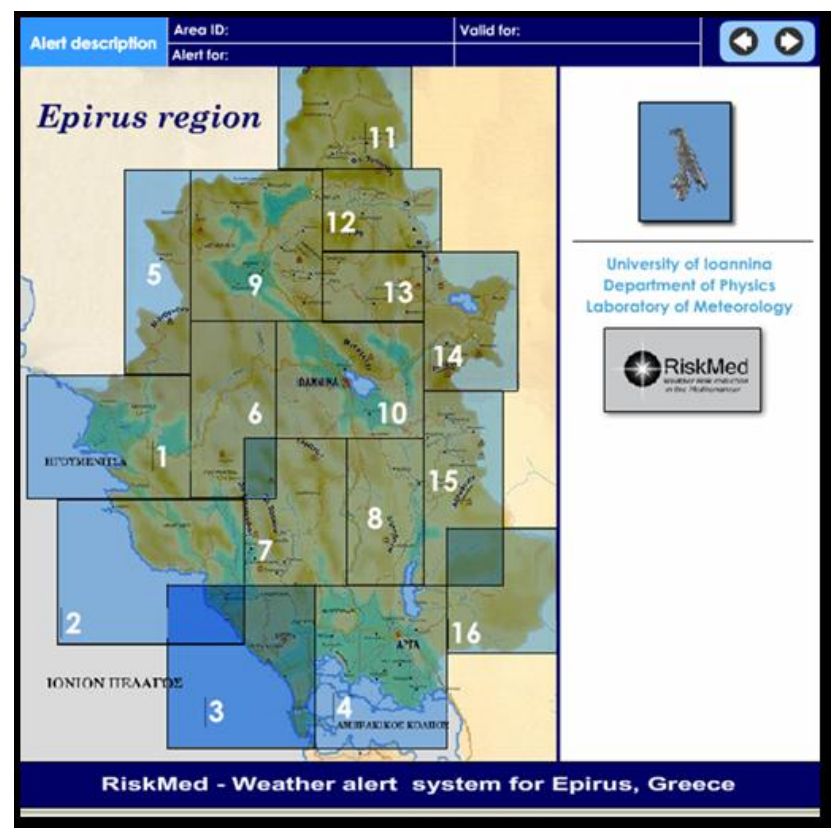

Fig. 2. The 16 sub-regions of Epirus.

correctly predicted, adjusted for hits associated with random chance. HK answers the question "How well did the forecast separate the "yes" events from the "no" events?" HSS measures the fraction of correct forecasts after eliminating those which would be correct due purely to random chance. Finally, OR measures the ratio of the odds of making a hit to the odds of making a false alarm.

As stated in the Introduction, the temperature, precipitation and wind speed outputs of the model are used as an input for a severe weather event warning system. The area of NW Greece has been divided in 16 sub-regions, taking into account the morphological and population characteristics (Fig. 2) and the warning system is applied for each subregion separately. When the value of a meteorological parameter, at one or more grid points of a sub-region during a 6-h period, is forecasted to be beyond specific thresholds, a yellow, orange or red warning is set for this particular subregion, depending on the severity of the event. Warnings have been set for extremely high/low temperature, high wind speed, heavy precipitation, large snowfall amounts and thunderstorms. The snowfall warnings correspond to extreme precipitation amounts associated with air temperature below $2{ }^{\circ} \mathrm{C}$, while the thunderstorm warnings correspond to extreme precipitation amounts being convective at a percentage higher than $50 \%$ of the total amounts. Because of the mountainous topography of Epirus, snowfall warnings are issued only when snowfall is forecasted below specific altitudes $(400 \mathrm{~m}, 700 \mathrm{~m}$, and $1000 \mathrm{~m}$ for coastal, inland and mountainous sub-regions, respectively), in order to avoid false alarms. The thresholds for the various meteorological parameters are shown in Table 1. They have been defined by taking into 
Table 1. Thresholds for the severe weather event alerts.

\begin{tabular}{lccc}
\hline Parameter & Yellow level & Orange level & Red level \\
\hline Wind speed (Beaufort) & $7-8$ & $8-9$ & $>9$ \\
Precipitation $(\mathrm{mm} / 6 \mathrm{~h})$ & $8-15$ & $15-30$ & $>30$ \\
Thunderstorm $(\mathrm{mm} / 6 \mathrm{~h}-50 \%$ convective $)$ & $8-15$ & $15-30$ & $>30$ \\
High Air Temperature $\left({ }^{\circ} \mathrm{C}\right)$ & $33-36$ & $36-39$ & $>39$ \\
Low Air Temperature $\left({ }^{\circ} \mathrm{C}\right)$ & $(-4)-(+2)$ & $(-8)-(-4)$ & $<(-8)$ \\
Snowfall $(\mathrm{mm} / 6 \mathrm{~h})\left(\right.$ air temperature $\left.<2^{\circ} \mathrm{C}\right)$ & $3-8$ & $8-15$ & $>15$ \\
\hline
\end{tabular}
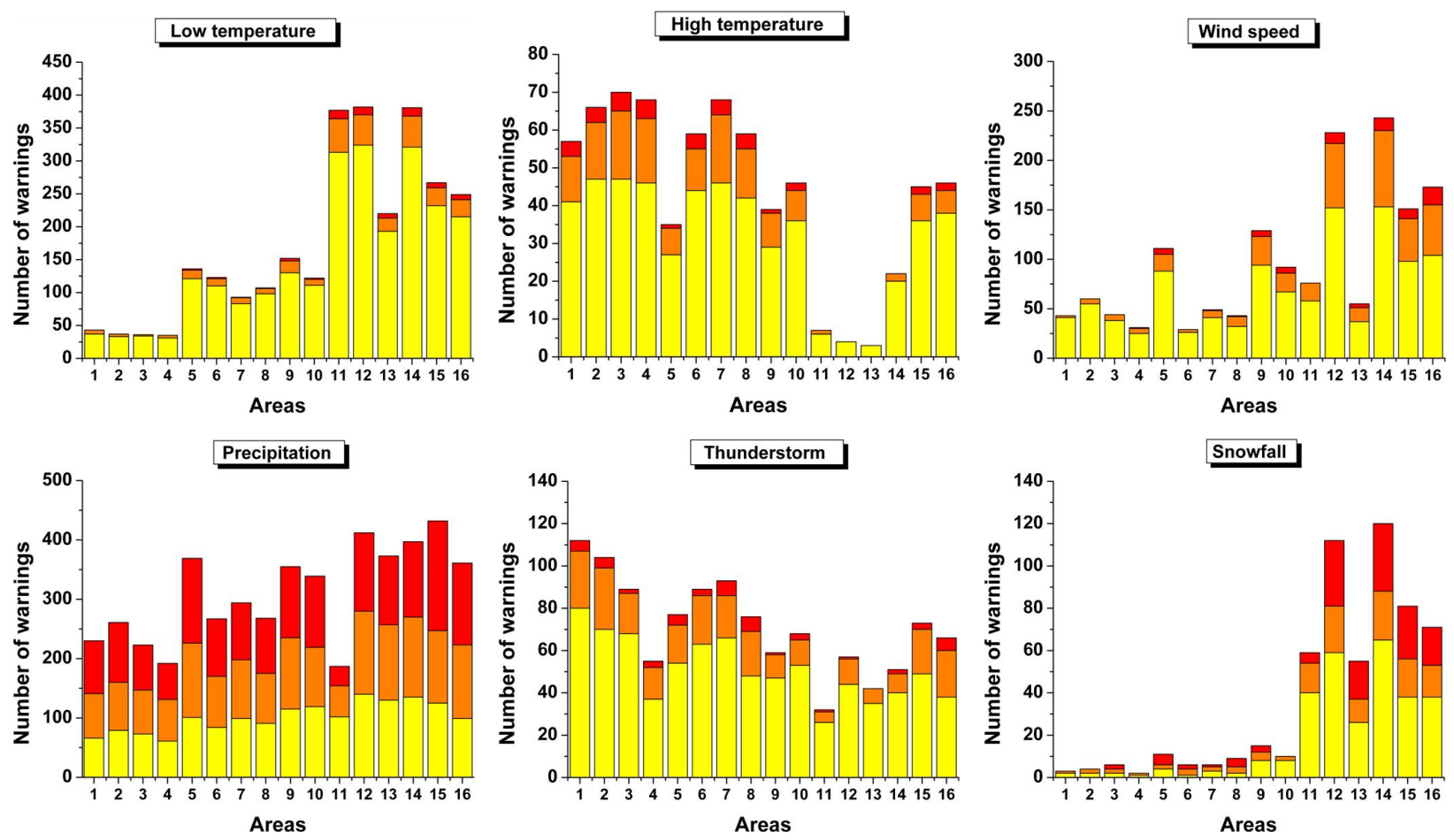

Fig. 3. Yellow, orange and red warnings for each event and each sub-region of Epirus for the under study year.

account the climatic records of the analyzed region and the effect of specific meteorological conditions on human activities.

The verification of thunderstorm activity is performed for the 16 sub-regions, using again a $2 \times 2$ (yes/no) contingency table and computing several statistical parameters. For the construction of the table, a "yes" forecast corresponds to a thunderstorm warning (yellow, orange or red) inside each sub-region, while a "yes" observation corresponds to the detection of lightning within this sub-region. Since the warnings are provided by the early warning system at 6-h intervals, this time interval is used as the verification time interval. Analyses of the one year lightning data have shown that most of the observed lightning occurs over the study area during the warm period of the year and especially between 12:0018:00 UTC. Therefore, the verification is performed for this specific time window, using the model-based warning issued the same day, (simulation period between $t+12$ and $t+18$ ) and the day before (simulation period between $t+36$ and $t+42$ ).

\section{Results}

\subsection{Overview of RISKMED issued warnings}

At first, a brief overview of the number of warnings issued by the system during the studied period is presented. As stated in the Introduction, when temperature, wind speed or precipitation forecast exceeds the defined thresholds (Table 1) in one of the 16 sub-regions (Fig. 2), yellow, orange or red alerts are issued accordingly. In Fig. 3, the histograms of the number of yellow, orange and red alerts for each event are presented. Most of the low temperature warnings refer, as 
expected, to the mountainous regions, while most of the high temperature ones are issued for the low altitude regions. For precipitation, most of the warnings correspond to the mountainous areas, while for the thunderstorm warnings, there is no clear geographical preference. However, monthly analysis (not shown) revealed that during winter, warnings are more frequent in the coastal sub-regions, while during summer, in the continental sub-regions. For snowfall, a very high percentage of the warnings correspond to the mountainous regions and only a small number of them to the sea and low altitude regions. Finally, for wind speed, it is shown that most of the warnings correspond to the high altitude areas, as wind speed generally increases over high terrain.

The frequency distribution of yellow, orange and red warnings for high/low temperatures, high wind speed and thunderstorms are supposed to follow the rule that frequency has to be generally maximum for yellow and minimum for red warnings. This is in agreement with the fact that the values of most meteorological parameters including air temperature follow the normal distribution. This is not the case for high precipitation and snowfall amount warnings. Specifically, for precipitation, red warnings are more than the yellow ones in some areas, while for snowfall the number of orange warnings in the high altitude areas is the minimum, instead of the number of the red ones. Thus, this is an indication that possible corrections should be made regarding the threshold definition of the above parameters, as it is more rational to issue less red than orange alerts. However, this has to be done with caution and after some additional years of results as, on the one hand, Epirus is the rainiest part of Greece and, on the other, daily precipitation amounts do not follow the normal distribution (Katsoulis and Pappas, 2000).

\subsection{Verification of temperature and wind forecasts}

The 2-m temperature observations of the three meteorological stations are compared with the outputs of the model Grid 3 at the grid points that are closest to each station. The differences in altitude between the stations and the corresponding grid points are around $10 \mathrm{~m}$, not affecting the results. The comparison is performed at 04:00 and 12:00 UTC. More specifically, the 04:00 and 12:00 UTC air temperature values at the three stations are compared with the corresponding $t+4 / t+28$ and $t+12 / t+36$ model forecasts, respectively (Figs. 4-6). Correlation coefficients, biases and standard deviations of the differences are presented in Table 2. It is shown that the correlation coefficients are highest for 12:00 UTC air temperatures, while the early morning (04:00 UTC) air temperature is overestimated by the model, especially in the area of Ioannina, where the bias is $6^{\circ} \mathrm{C}$ for the $\mathrm{t}+4$ forecast and $5.2{ }^{\circ} \mathrm{C}$ for the $\mathrm{t}+28$ forecast. The 12:00 UTC temperature is also overestimated, but the bias does not exceed $1.5^{\circ} \mathrm{C}$ for the $\mathrm{t}+12$ and $0.8^{\circ} \mathrm{C}$ for the $\mathrm{t}+36$ forecast. The significant overestimation of the early morning temperature, especially in the inland regions, could be probably attributed to the fact that radiative cooling of the ground and the corresponding surface temperature inversion is not satisfactorily simulated by the model and this may be associated with either the specific reflection or radiation properties of the ground material. As it concerns the other two stations (Arta and Igoumenitsa), the bias is significantly reduced, especially for the noon time forecasts (for the $t+12$ and $t+36$ forecasts).

The same procedure is followed for the verification of wind speed forecasts (Figs. 7-9). The 10-m height wind speed outputs of MM5 have been modified according to the surface roughness and the anemometers height, in order to be comparable with the wind speed records of the surface stations. It is shown (Table 2), that the correlation coefficients for the 12:00 UTC wind speed are generally low, hardly exceeding 0.5 . The considerably low correlation coefficients must be due to the fact that wind is a very sensitive meteorological parameter. Wind is strongly affected by local smallscale geomorphological characteristics (natural and artificial) and the associated micrometeorological effects, not satisfactorily simulated by the model because of the low (relatively to the size of the above mentioned characteristics) resolution of Grid 3. Further, the model slightly overestimates the wind speed at all three stations with biases ranging between 0.8 and $1.6 \mathrm{~m} / \mathrm{s}$ at 12:00 UTC. The effect of the additional surface roughness due to the above local characteristics (e.g. hills, buildings and trees) on the station wind speed records seems to be dominant here.

\subsection{Verification of the precipitation forecasts}

For daily accumulated precipitation, the comparison between the model results and the station observations is graphically presented in Fig. 10. The correlation coefficients are not calculated because of the too many zero values, generating a data distribution significantly deviating from the normal one. The biases are presented in Table 2 and range from $-0.4 \mathrm{~mm}$ in Ioannina to $+0.2 \mathrm{~mm}$ in Igoumenitsa. The effect of static instability over the land (in summer) and/or potential instability of the ascending air masses on the windward slopes of the Pindus Mountains (in winter) on precipitation seems to be slightly underestimated by the model, as the forecast precipitation amounts are lower than those recorded at the two inland stations and higher than the observed at the coastal station. Categorical statistics of the contingency tables for $2,8,15$, and $30 \mathrm{~mm}$ daily precipitation thresholds are presented in Table 3. Bias scores indicate that for $2 \mathrm{~mm}$ threshold, the model forecasts precipitation correctly as its values are close to 1 (1.00 for Ioannina, 0.97 for Arta, and 1.06 for Igoumenitsa). For the highest threshold $(30 \mathrm{~mm})$ precipitation is not forecasted so accurately $(0.50,1.17$, and 1.13$)$ but it has to be noted that the total number of cases is very small (4, 6, and 8). The ETS, in general, also decreases with increasing threshold and it ranges from 0.54 to 0.20 . It is shown that $\mathrm{AC}$, and POFD values are close to the perfect 

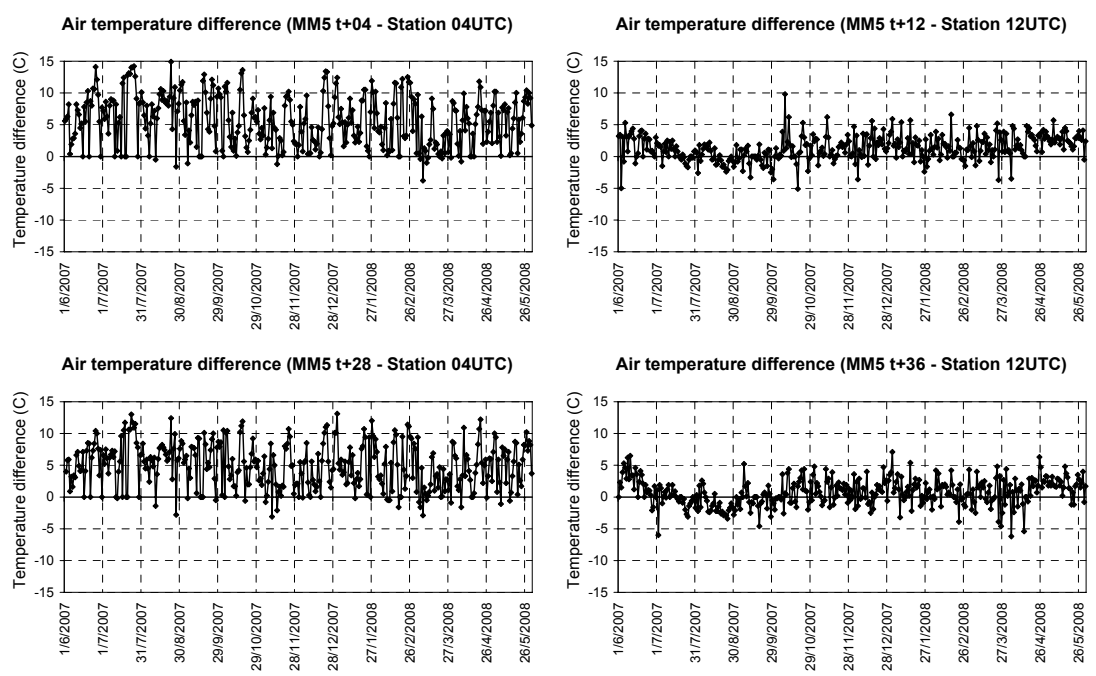

Fig. 4. Verification of air temperature forecast for Ioannina.
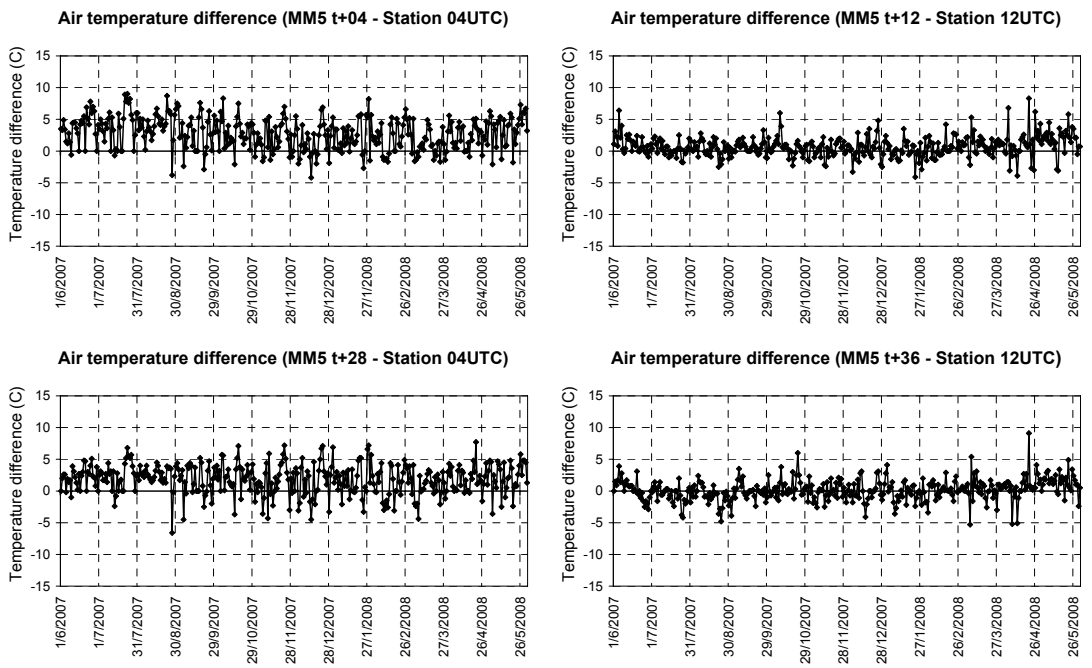

Fig. 5. As in Fig. 4, but for Igoumenitsa.
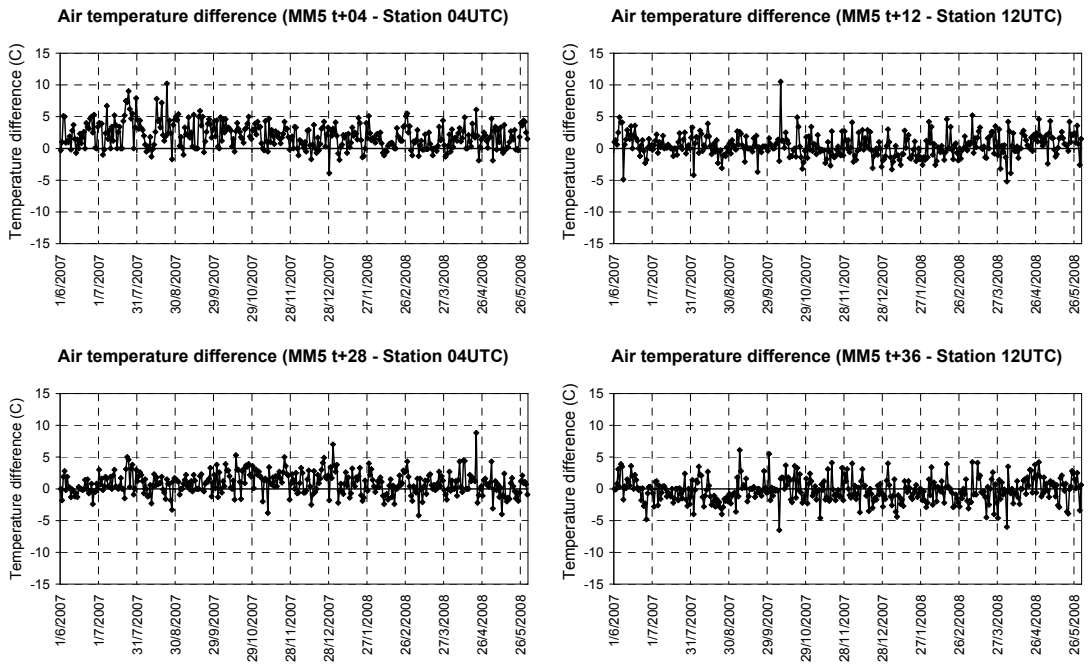

Fig. 6. As in Fig. 4, but for Arta.

Nat. Hazards Earth Syst. Sci., 10, 383-394, 2010

www.nat-hazards-earth-syst-sci.net/10/383/2010/ 
Table 2. Correlation coefficients between forecast and observed values, biases and standard deviations of the differences. Biases and standard deviations are given in ${ }^{\circ} \mathrm{C}$ for air temperature, in $\mathrm{m} / \mathrm{s}$ for wind speed and in $\mathrm{mm}$ for precipitation amount.

\begin{tabular}{|c|c|c|c|c|c|c|c|c|c|}
\hline \multirow[b]{2}{*}{ Parameters } & \multicolumn{3}{|c|}{ Ioannina } & \multicolumn{3}{|c|}{ Igoumenitsa } & \multicolumn{3}{|c|}{ Arta } \\
\hline & $R$ & bias & Std & $R$ & bias & Std & $R$ & bias & Std \\
\hline Temp t+4 (MM5) - Temp 04:00 UTC (station) & 0.83 & 6.0 & 3.6 & 0.93 & 2.9 & 2.4 & 0.96 & 2.1 & 2.0 \\
\hline Temp t+12 (MM5) - Temp 12:00 UTC (station) & 0.98 & 1.4 & 2.0 & 0.98 & 0.7 & 1.7 & 0.98 & 0.4 & 1.9 \\
\hline Temp t+28 (MM5) - Temp 04:00 UTC (station) & 0.85 & 5.2 & 3.5 & 0.92 & 2.0 & 2.4 & 0.96 & 0.9 & 1.8 \\
\hline Temp t+36 (MM5) - Temp 12:00 UTC (station) & 0.97 & 0.8 & 2.2 & 0.98 & 0.2 & 1.8 & 0.97 & 0.3 & 2.0 \\
\hline Windsp t+12 (MM5) - Windsp 12:00 UTC (station) & 0.53 & 0.8 & 1.5 & 0.49 & 1.4 & 1.5 & 0.54 & 1.4 & 1.8 \\
\hline Windsp t+36 (MM5) - Windsp 12:00 UTC (station) & 0.52 & 0.9 & 1.6 & 0.48 & 1.6 & 1.6 & 0.46 & 1.5 & 1.9 \\
\hline Precipitation (24-h) & - & -0.4 & 4.8 & - & 0.2 & 5.8 & - & -0.1 & 4.7 \\
\hline Precipitation 00:00-06:00 UTC & - & -0.2 & 1.6 & - & -0.0 & 2.5 & - & -0.3 & 2.9 \\
\hline Precipitation 06:00-12:00 UTC & - & 0.0 & 1.3 & - & 0.4 & 3.2 & - & 0.2 & 2.2 \\
\hline Precipitation 12:00-18:00 UTC & - & -0.1 & 3.2 & - & -0.1 & 2.7 & - & 0.1 & 2.4 \\
\hline Precipitation 18:00-24:00 UTC & - & -0.2 & 2.5 & - & -0.0 & 3.0 & - & -0.1 & 2.4 \\
\hline
\end{tabular}
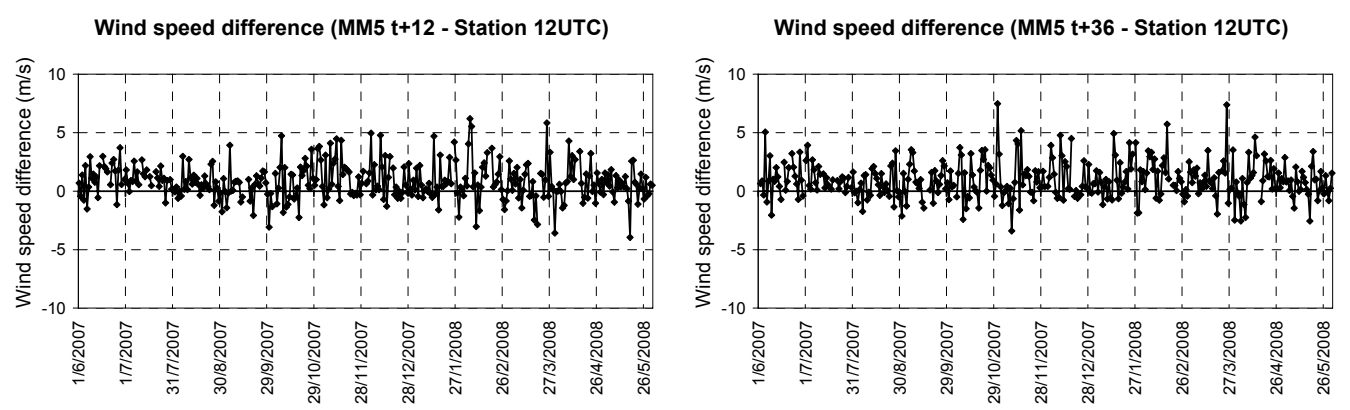

Fig. 7. Verification of wind speed forecast for Ioannina.
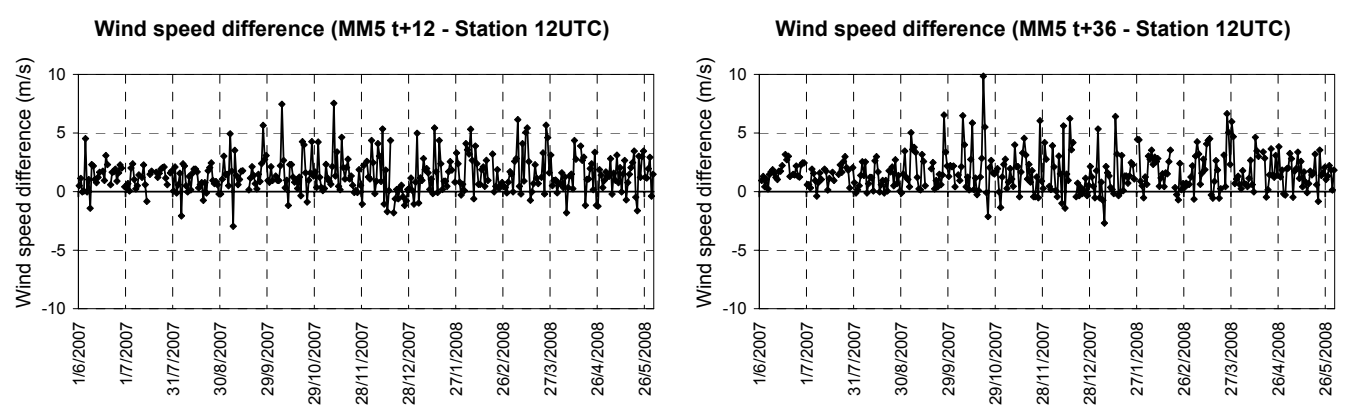

Fig. 8. As in Fig. 7, but for Igoumenitsa.
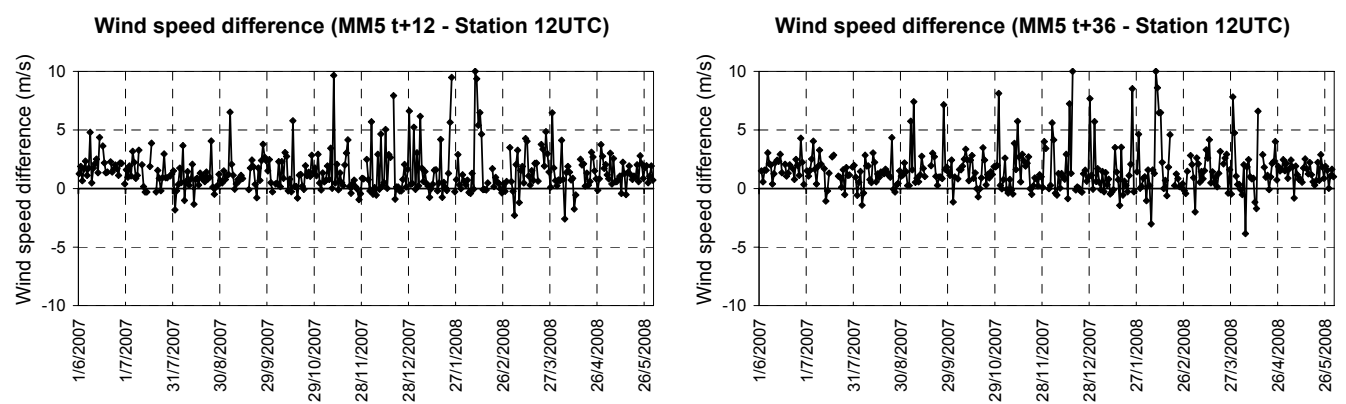

Fig. 9. As in Fig. 7, but for Arta. 
Table 3. Categorical statistics for 24-h accumulated precipitation.

\begin{tabular}{|c|c|c|c|c|c|c|c|c|c|c|c|c|c|c|}
\hline \multirow{3}{*}{$\begin{array}{l}\text { Categorical } \\
\text { statistics }\end{array}$} & \multicolumn{12}{|c|}{ Daily (24 h) } & \multirow{3}{*}{ Range } & \multirow{3}{*}{$\begin{array}{l}\text { Perfect } \\
\text { score }\end{array}$} \\
\hline & \multicolumn{4}{|c|}{ Ioannina } & \multicolumn{4}{|c|}{ Arta } & \multicolumn{4}{|c|}{ Igoumenitsa } & & \\
\hline & $\begin{array}{c}\geq \\
2 \mathrm{~mm}\end{array}$ & $\begin{array}{l}\geq \\
8 \mathrm{~mm}\end{array}$ & $\begin{array}{c}\geq \\
15 \mathrm{~mm}\end{array}$ & $\begin{array}{c}\geq \\
30 \mathrm{~mm}\end{array}$ & $\begin{array}{c}\geq \\
2 \mathrm{~mm}\end{array}$ & $\begin{array}{l}\geq \\
8 \mathrm{~mm}\end{array}$ & $\begin{array}{c}\geq \\
15 \mathrm{~mm}\end{array}$ & $\begin{array}{c}\geq \\
30 \mathrm{~mm}\end{array}$ & $\begin{array}{c}\geq \\
2 \mathrm{~mm}\end{array}$ & $\begin{array}{c}\geq \\
8 \mathrm{~mm}\end{array}$ & $\begin{array}{c}\geq \\
15 \overline{\mathrm{mm}}\end{array}$ & $\begin{array}{c}\geq \\
30 \overline{\mathrm{mm}}\end{array}$ & & \\
\hline $\mathrm{AC}$ & 0.88 & 0.93 & 0.95 & 0.99 & 0.88 & 0.94 & 0.96 & 0.98 & 0.90 & 0.90 & 0.94 & 0.98 & $0-1$ & 1 \\
\hline BIAS & 1.00 & 0.81 & 0.82 & 0.50 & 0.97 & 0.95 & 0.83 & 1.17 & 1.06 & 1.13 & 0.91 & 1.13 & 0-Inf. & 1 \\
\hline POD & 0.69 & 0.57 & 0.41 & 0.25 & 0.67 & 0.71 & 0.50 & 0.50 & 0.77 & 0.63 & 0.45 & 0.63 & $0-1$ & 1 \\
\hline FAR & 0.31 & 0.30 & 0.50 & 0.50 & 0.31 & 0.25 & 0.40 & 0.57 & 0.27 & 0.44 & 0.50 & 0.44 & $0-1$ & 0 \\
\hline POFD & 0.08 & 0.03 & 0.02 & 0.00 & 0.07 & 0.03 & 0.02 & 0.01 & 0.07 & 0.06 & 0.03 & 0.01 & $0-1$ & 0 \\
\hline CSI & 0.53 & 0.46 & 0.29 & 0.20 & 0.52 & 0.57 & 0.38 & 0.30 & 0.60 & 0.42 & 0.31 & 0.42 & $0-1$ & 1 \\
\hline ETS & 0.44 & 0.42 & 0.27 & 0.20 & 0.44 & 0.54 & 0.35 & 0.29 & 0.52 & 0.37 & 0.28 & 0.41 & $-1 / 3-1$ & 1 \\
\hline $\mathrm{HK}$ & 0.62 & 0.54 & 0.39 & 0.25 & 0.60 & 0.68 & 0.48 & 0.49 & 0.70 & 0.57 & 0.42 & 0.61 & $-1-(1)$ & 1 \\
\hline HSS & 0.62 & 0.59 & 0.43 & 0.33 & 0.61 & 0.70 & 0.52 & 0.45 & 0.68 & 0.54 & 0.44 & 0.58 & -Inf.-1 & 1 \\
\hline OR & 27.39 & 43.75 & 32.20 & 113.67 & 26.49 & 81.55 & 53.67 & 84.00 & 43.20 & 26.08 & 26.17 & 139.17 & 0-Inf & Inf. \\
\hline Cases (obs) & 70 & 38 & 18 & 4 & 69 & 38 & 18 & 6 & 73 & 39 & 23 & 8 & & \\
\hline
\end{tabular}
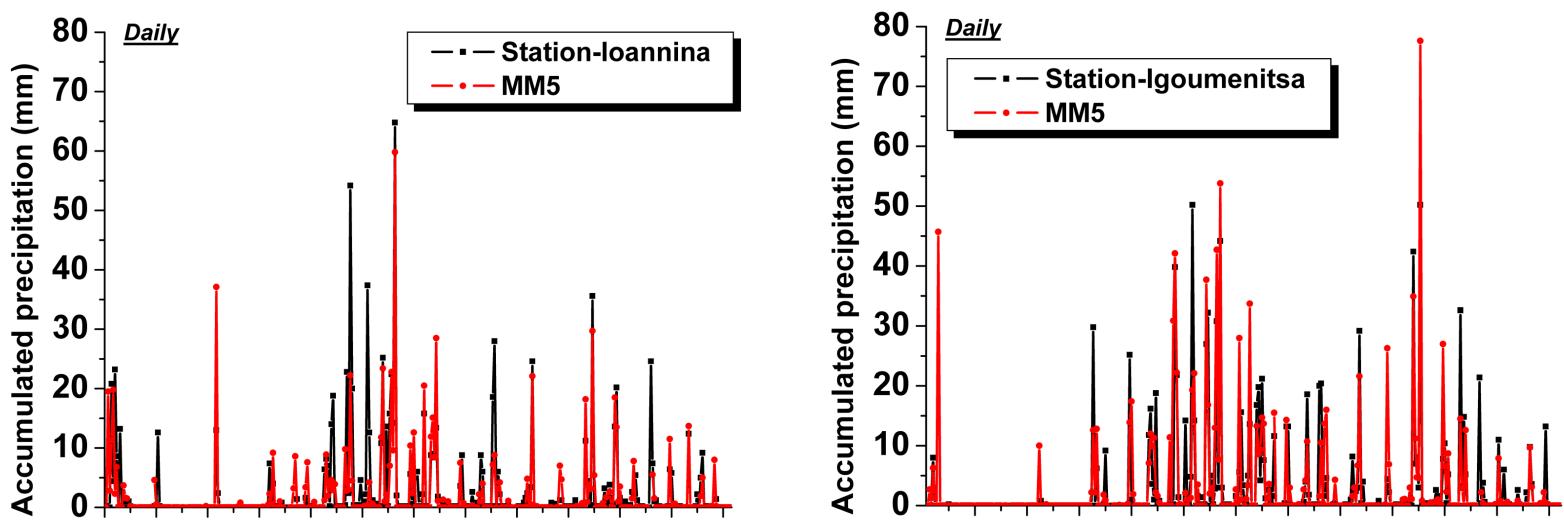

(a)

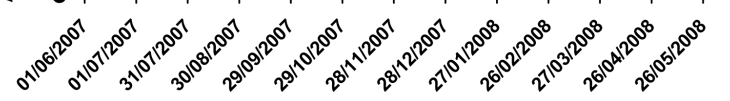

(b)
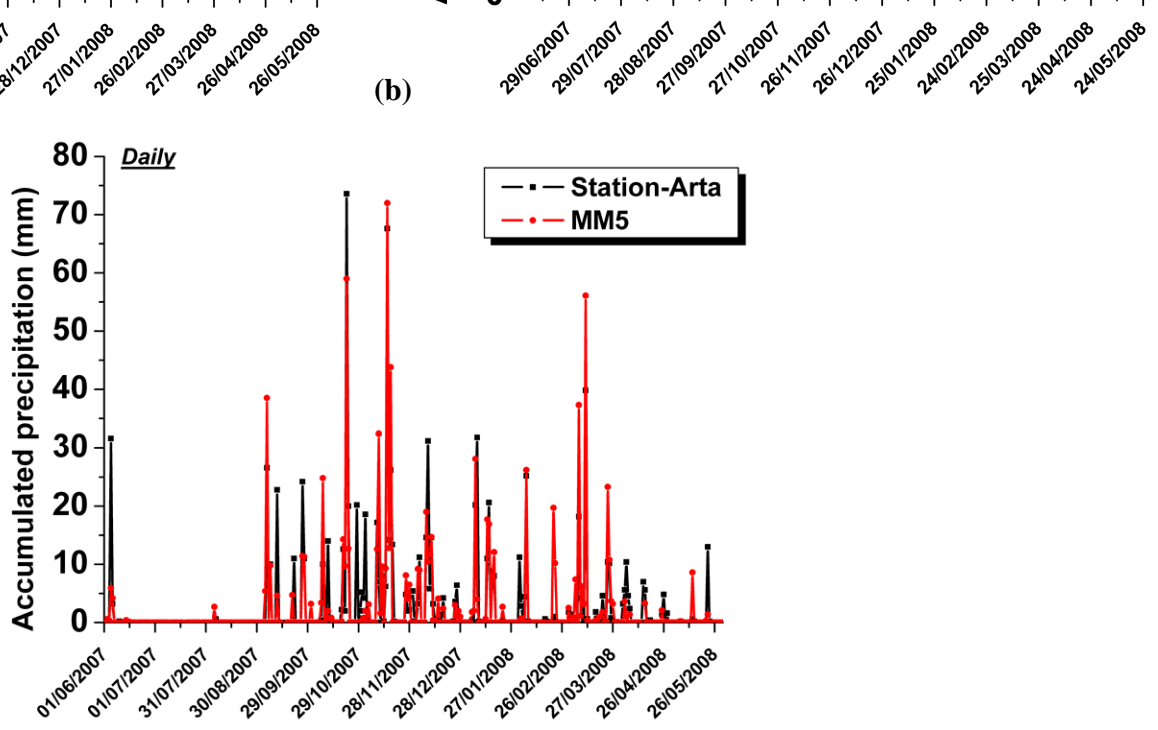

Fig. 10. Verification of the 24-h precipitation forecasts for: (a) Ioannina, (b) Igoumenitsa, and (c) Arta. 
Table 4a. Categorical statistics for the first 6-hour interval (00:00-06:00 UTC) accumulated precipitation.

\begin{tabular}{|c|c|c|c|c|c|c|c|c|c|c|c|}
\hline \multirow{3}{*}{$\begin{array}{l}\text { Categorical } \\
\text { statistics }\end{array}$} & \multicolumn{11}{|c|}{ First 6-h interval (00:00-06:00 UTC) } \\
\hline & \multicolumn{3}{|c|}{ Ioannina } & \multicolumn{3}{|c|}{ Arta } & \multicolumn{3}{|c|}{ Igoumenitsa } & \multirow[t]{2}{*}{ Range } & \multirow{2}{*}{$\begin{array}{c}\text { Perfect } \\
\text { score }\end{array}$} \\
\hline & $\begin{array}{c}\geq \\
2 \mathrm{~mm}\end{array}$ & $\begin{array}{c}\geq \\
8 \mathrm{~mm}\end{array}$ & $\underset{15 \mathrm{~mm}}{\geq}$ & $\begin{array}{c}\geq \\
2 \mathrm{~mm}\end{array}$ & $\begin{array}{c}\geq \\
8 \mathrm{~mm}\end{array}$ & $\begin{array}{c}\geq \\
15 \mathrm{~mm}\end{array}$ & $\begin{array}{c}\geq \\
2 \mathrm{~mm}\end{array}$ & $\begin{array}{c}\geq \\
8 \mathrm{~mm}\end{array}$ & $\begin{array}{c}\geq \\
15 \mathrm{~mm}\end{array}$ & & \\
\hline $\mathrm{AC}$ & 0.95 & 0.99 & 1.00 & 0.95 & 0.98 & 0.99 & 0.95 & 0.97 & 0.99 & $0-1$ & 1 \\
\hline BIAS & 0.78 & 0.86 & 0.50 & 0.78 & 0.75 & 0.40 & 0.89 & 0.90 & 1.33 & 0-Inf. & 1 \\
\hline POD & 0.48 & 0.57 & 0.50 & 0.56 & 0.38 & 0.20 & 0.59 & 0.50 & 0.33 & $0-1$ & 1 \\
\hline FAR & 0.39 & 0.33 & 0.00 & 0.29 & 0.50 & 0.50 & 0.33 & 0.44 & 0.75 & $0-1$ & 0 \\
\hline POFD & 0.02 & 0.01 & 0.00 & 0.02 & 0.01 & 0.00 & 0.03 & 0.01 & 0.01 & $0-1$ & 0 \\
\hline CSI & 0.37 & 0.44 & 0.50 & 0.45 & 0.27 & 0.17 & 0.46 & 0.36 & 0.17 & $0-1$ & 1 \\
\hline ETS & 0.34 & 0.44 & 0.50 & 0.43 & 0.26 & 0.16 & 0.43 & 0.34 & 0.16 & $-1 / 3-1$ & 1 \\
\hline HK & 0.46 & 0.57 & 0.50 & 0.54 & 0.37 & 0.20 & 0.57 & 0.49 & 0.32 & $-1-(1)$ & 1 \\
\hline HSS & 0.51 & 0.61 & 0.67 & 0.60 & 0.42 & 0.28 & 0.60 & 0.51 & 0.28 & -Inf.-1 & 1 \\
\hline OR & 41.38 & 224.67 & Inf. & 65.21 & 67.00 & 85.00 & 56.55 & 83.00 & 56.67 & 0-Inf & Inf. \\
\hline Cases (obs) & 24 & 7 & 2 & 27 & 8 & 5 & 27 & 10 & 3 & & \\
\hline
\end{tabular}

Table 4b. Categorical statistics for the second 6-h interval (06:00-12:00 UTC) accumulated precipitation.

\begin{tabular}{|c|c|c|c|c|c|c|c|c|c|c|c|}
\hline \multirow{3}{*}{$\begin{array}{l}\text { Categorical } \\
\text { statistics }\end{array}$} & \multicolumn{11}{|c|}{ Second 6-h interval (06:00-12:00 UTC) } \\
\hline & \multicolumn{3}{|c|}{ Ioannina } & \multicolumn{3}{|c|}{ Arta } & \multicolumn{3}{|c|}{ Igoumenitsa } & \multirow[t]{2}{*}{ Range } & \multirow{2}{*}{$\begin{array}{c}\text { Perfect } \\
\text { score }\end{array}$} \\
\hline & $\begin{array}{c}\geq \\
2 \mathrm{~mm}\end{array}$ & $\begin{array}{c}\geq \\
8 \mathrm{~mm}\end{array}$ & $\begin{array}{c}\geq \\
15 \mathrm{~mm}\end{array}$ & $\begin{array}{c}\geq \\
2 \mathrm{~mm}\end{array}$ & $\begin{array}{c}\geq \\
8 \mathrm{~mm}\end{array}$ & $\begin{array}{c}\geq \\
15 \mathrm{~mm}\end{array}$ & $\begin{array}{c}\geq \\
2 \mathrm{~mm}\end{array}$ & $\begin{array}{c}\geq \\
8 \mathrm{~mm}\end{array}$ & $\begin{array}{c}\geq \\
15 \mathrm{~mm}\end{array}$ & & \\
\hline $\mathrm{AC}$ & 0.96 & 0.98 & 1.00 & 0.94 & 0.99 & 1.00 & 0.93 & 0.96 & 0.99 & $0-1$ & 1 \\
\hline BIAS & 0.88 & 1.14 & 1.50 & 1.26 & 0.88 & 0.67 & 1.44 & 1.71 & 2.00 & 0-Inf. & 1 \\
\hline POD & 0.67 & 0.57 & 1.00 & 0.58 & 0.63 & 0.67 & 0.76 & 0.43 & 0.67 & $0-1$ & 1 \\
\hline FAR & 0.24 & 0.50 & 0.33 & 0.54 & 0.29 & 0.00 & 0.47 & 0.75 & 0.67 & $0-1$ & 0 \\
\hline POFD & 0.02 & 0.01 & 0.00 & 0.04 & 0.01 & 0.00 & 0.05 & 0.03 & 0.01 & $0-1$ & 0 \\
\hline CSI & 0.55 & 0.36 & 0.67 & 0.34 & 0.50 & 0.67 & 0.45 & 0.19 & 0.29 & $0-1$ & 1 \\
\hline ETS & 0.53 & 0.35 & 0.66 & 0.32 & 0.49 & 0.66 & 0.42 & 0.17 & 0.28 & $-1 / 3-1$ & 1 \\
\hline HK & 0.65 & 0.56 & 1.00 & 0.54 & 0.62 & 0.67 & 0.71 & 0.40 & 0.66 & $-1-(1)$ & 1 \\
\hline HSS & 0.69 & 0.52 & 0.80 & 0.48 & 0.66 & 0.80 & 0.59 & 0.30 & 0.44 & -Inf.-1 & 1 \\
\hline OR & 126.80 & 111.67 & Inf. & 33.21 & 280.00 & Inf. & 56.63 & 27.50 & 169.50 & $0-$ Inf & Inf. \\
\hline Cases (obs) & 26 & 7 & 2 & 19 & 8 & 3 & 26 & 8 & 3 & & \\
\hline
\end{tabular}

scores for all thresholds. This means that the model is skillful in reproducing correct forecasts of precipitation at a percentage close or better than $90 \%$, while the fraction of incorrectly forecasted events when no event was observed is also very low (lower than $8 \%$ for all thresholds and stations). OR value for Igoumenitsa is remarkably high for $30 \mathrm{~mm}$ threshold, showing that the ratio of the odds of making a hit to the odds of making a false alarm is remarkably higher for the high precipitation amounts. In general, POD, CSI, ETS, HK and HSS values decrease as the precipitation threshold increases with few exceptions only.
The same verification process has been followed for the four 6-h intervals of the day. The results are presented in Table $4 \mathrm{a}-\mathrm{d}$. In this case, the $30 \mathrm{~mm}$ threshold has been omitted because of the too low number of events. For the same reason, the results for the $15 \mathrm{~mm}$ threshold cannot be considered robust. A detailed examination of Table 4 reveals that there is not a clear trend towards lower or higher values as threshold and time change. However, in general, it could be argued that precipitation forecast appears slightly better for the second 6-h interval (06:00-12:00) and somewhat worse for the last 6-h interval (18:00-24:00). These results compared 
Table 4c. Categorical statistics for the third 6-h interval (12:00-18:00 UTC) accumulated precipitation.

\begin{tabular}{|c|c|c|c|c|c|c|c|c|c|c|c|}
\hline \multirow{3}{*}{$\begin{array}{l}\text { Categorical } \\
\text { statistics }\end{array}$} & \multicolumn{11}{|c|}{ Third 6-h interval (12:00-18:00 UTC) } \\
\hline & \multicolumn{3}{|c|}{ Ioannina } & \multicolumn{3}{|c|}{ Arta } & \multicolumn{3}{|c|}{ Igoumenitsa } & \multirow[t]{2}{*}{ Range } & \multirow{2}{*}{$\begin{array}{r}\text { Perfect } \\
\text { score }\end{array}$} \\
\hline & $\underset{2 \mathrm{~mm}}{\geq}$ & $\begin{array}{c}\geq \\
8 \mathrm{~mm}\end{array}$ & $\begin{array}{c}\geq \\
15 \mathrm{~mm}\end{array}$ & $\underset{2 \mathrm{~mm}}{\geq}$ & $\underset{8 \mathrm{~mm}}{\geq}$ & $\underset{15 \mathrm{~mm}}{\geq}$ & $\underset{2 \mathrm{~mm}}{\geq}$ & $\underset{8 \mathrm{~mm}}{\geq}$ & $\underset{15 \mathrm{~mm}}{\geq}$ & & \\
\hline $\mathrm{AC}$ & 0.91 & 0.96 & 0.98 & 0.92 & 0.97 & 0.99 & 0.91 & 0.96 & 0.98 & $0-1$ & 1 \\
\hline BIAS & 1.16 & 0.58 & 0.67 & 1.38 & 0.82 & 0.80 & 1.00 & 0.50 & 0.60 & 0 -Inf. & 1 \\
\hline POD & 0.58 & 0.25 & 0.33 & 0.69 & 0.36 & 0.60 & 0.47 & 0.31 & 0.20 & $0-1$ & 1 \\
\hline FAR & 0.50 & 0.57 & 0.50 & 0.50 & 0.56 & 0.25 & 0.53 & 0.38 & 0.67 & $0-1$ & 0 \\
\hline POFD & 0.06 & 0.01 & 0.01 & 0.06 & 0.01 & 0.00 & 0.05 & 0.01 & 0.01 & $0-1$ & 0 \\
\hline CSI & 0.37 & 0.19 & 0.25 & 0.41 & 0.25 & 0.50 & 0.30 & 0.26 & 0.14 & $0-1$ & 1 \\
\hline ETS & 0.32 & 0.17 & 0.24 & 0.37 & 0.24 & 0.50 & 0.26 & 0.25 & 0.14 & $-1 / 3-1$ & 1 \\
\hline HK & 0.52 & 0.24 & 0.33 & 0.64 & 0.35 & 0.60 & 0.42 & 0.30 & 0.19 & $-1-(1)$ & 1 \\
\hline HSS & 0.59 & 0.30 & 0.39 & 0.54 & 0.38 & 0.66 & 0.42 & 0.40 & 0.24 & - Inf.-1 & 1 \\
\hline OR & 22.85 & 27.50 & 84.50 & 37.75 & 37.71 & 510.00 & 16.41 & 49.55 & 42.38 & $0-$ Inf & Inf. \\
\hline Cases (obs) & 32 & 12 & 6 & 26 & 11 & 5 & 31 & 17 & 5 & & \\
\hline
\end{tabular}

Table 4d. Categorical statistics for the fourth 6-h interval (18:00-24:00 UTC) accumulated precipitation.

\begin{tabular}{|c|c|c|c|c|c|c|c|c|c|c|c|}
\hline \multirow{3}{*}{$\begin{array}{l}\text { Categorical } \\
\text { statistics }\end{array}$} & \multicolumn{11}{|c|}{ Fourth 6-h interval (18:00-24:00 UTC) } \\
\hline & \multicolumn{3}{|c|}{ Ioannina } & \multicolumn{3}{|c|}{ Arta } & \multicolumn{3}{|c|}{ Igoumenitsa } & \multirow[t]{2}{*}{ Range } & \multirow{2}{*}{$\begin{array}{l}\text { Perfect } \\
\text { score }\end{array}$} \\
\hline & $\underset{2 \mathrm{~mm}}{\geq}$ & $\underset{8 \mathrm{~mm}}{\geq}$ & $\underset{15 \mathrm{~mm}}{\geq}$ & $\begin{array}{c}\geq \\
2 \mathrm{~mm}\end{array}$ & $\stackrel{\geq}{8 \mathrm{~mm}}$ & $\underset{15 \mathrm{~mm}}{\geq}$ & $\begin{array}{c}\geq \\
2 \mathrm{~mm}\end{array}$ & $\underset{8 \mathrm{~mm}}{\geq}$ & $\underset{15 \mathrm{~mm}}{\geq}$ & & \\
\hline $\mathrm{AC}$ & 0.91 & 0.97 & 0.99 & 0.91 & 0.97 & 0.99 & 0.91 & 0.96 & 0.98 & $0-1$ & 1 \\
\hline BIAS & 0.77 & 0.75 & 0.00 & 0.81 & 0.88 & 1.00 & 1.36 & 0.60 & 0.60 & 0-Inf. & 1 \\
\hline POD & 0.18 & 0.25 & 0.00 & 0.39 & 0.38 & 0.33 & 0.56 & 0.10 & 0.00 & $0-1$ & 1 \\
\hline FAR & 0.76 & 0.67 & - & 0.52 & 0.57 & 0.67 & 0.59 & 0.83 & 1.00 & $0-1$ & 0 \\
\hline POFD & 0.04 & 0.01 & 0.00 & 0.04 & 0.01 & 0.01 & 0.06 & 0.01 & 0.01 & $0-1$ & 0 \\
\hline CSI & 0.11 & 0.17 & 0.00 & 0.27 & 0.25 & 0.20 & 0.31 & 0.07 & 0.00 & $0-1$ & 1 \\
\hline ETS & 0.09 & 0.16 & 0.00 & 0.23 & 0.24 & 0.20 & 0.27 & 0.06 & -0.01 & $-1 / 3-1$ & 1 \\
\hline HK & 0.14 & 0.24 & 0.00 & 0.35 & 0.36 & 0.33 & 0.50 & 0.09 & -0.01 & $-1-(1)$ & 1 \\
\hline HSS & 0.16 & 0.27 & 0.00 & 0.38 & 0.39 & 0.33 & 0.43 & 0.11 & -0.01 & - Inf.-1 & 1 \\
\hline OR & 5.32 & 27.83 & - & 14.67 & 50.10 & 85.25 & 19.15 & 7.36 & 0.00 & $0-$ Inf & Inf. \\
\hline Cases (obs) & 23 & 9 & 3 & 33 & 8 & 3 & 26 & 10 & 5 & & \\
\hline
\end{tabular}

to those for the 24-h period (Table 3) appear poorer (except maybe for the 06:00-12:00 6-h), as was expected, because of the higher requirement in terms of time-accuracy.

It has to be underlined that the selection of the above thresholds $(2,8,15$, and $30 \mathrm{~mm})$, which are the same with the ones for the severe weather events warning system, does not imply that the verification of the precipitation forecasts can be considered as an indirect verification of the issued alerts. Epirus is a very mountainous area with a sparse rain gauge network and the 16 sub-regions defined cover areas of approximately $25 \times 25 \mathrm{~km}$ containing more than 150 grid points. For the same reason, verification of snowfall forecast has been avoided since the sub-areas 1, 4, and 10, where the three stations belong to, contain high altitude grid points where snowfall is apparently more frequent than in the cities (in the continental town of Ioannina the mean annual number of snowfall days is 7). Thus, the above results are representative for small areas around Ioannina, Arta and Igoumenitsa only. 


\subsection{Verification of thunderstorm warnings}

As already mentioned in Sect. 2, the verification of thunderstorm warnings is performed for all sub-regions, using as reference lightning measurements by the ZEUS lightning detection system. The verification of convective precipitation forecasts is really a challenging task that cannot be fulfilled by using raingauge observations, especially over regions such as Epirus where the surface network is not dense. For such a task, radar data would be needed but they are also not available in the area. For this reason, lightning data have been used as a proxy for the occurrence of convection in order to verify the RISKMED warnings of thunderstorms. Further, as long-range lightning detection networks suffer from underestimation of the number of flashes (Lagouvardos et al., 2009), a quantitative approach that incorporates thresholds for the number of lightning would not be possible. Therefore, the adopted verification procedure is limited to the qualitative measure of a yes/no for both the lightning and the thunderstorm warnings.

As reported in Table 1, thunderstorm warnings are issued if forecast precipitation amounts exceed $8 \mathrm{~mm}$ in $6 \mathrm{~h}$ and at least $50 \%$ of this amount is produced by the convective parameterization scheme. The contingency table for the verification of thunderstorms was constructed by considering a yes/no of the observation of at least one lightning in each sub-region and a yes/no of a forecasted thunderstorm warning of any level in the same sub-region. The calculation of the relevant scores reveals the following:

- For the simulations issued the same day (forecast interval $\mathrm{t}+12-\mathrm{t}+18$ ), POD equals 0.36 , FAR 0.30 and CSI 0.30 .

- For the simulations issued the previous day (forecast interval $t+36-t+42$ ), POD equals 0.29 , FAR 0.28 and CSI 0.27 .

As expected, thunderstorm forecasts are more skilful for shorter lead time. However, the statistical scores appear quite low. Therefore the statistical analysis was repeated, changing the thresholds given in Table 1 from 8 to $4 \mathrm{~mm}$ in $6 \mathrm{~h}$. The results show that:

- For the forecasts issued the same day $(\mathrm{t}+12-\mathrm{t}+18)$, POD equals 0.52 , FAR 0.38 and CSI 0.39 .

- For the forecasts issued the previous day $(t+36-t+42)$, POD equals 0.41, FAR 0.37 and CSI 0.33.

Therefore, the modified threshold provides more accurate forecasts of thunderstorm occurrence and it is suggested that in the operational procedure of RISKMED, this new threshold has to be adopted. However, it is reminded that these results do not use direct measurements of thunderstorm activity (a task that would demand a large number of manned stations) but remote observations of lightning activity.

\section{Conclusions}

The MM5 meteorological model is applied operationally for the area of NW Greece for the period 1 June 2007-31 May 2008 and the results are used in order to construct a severe weather event warning system. A verification of the model is carried out by comparing the model outputs with the records from three automatic meteorological stations. According to the verification results and the frequency of the warnings, the following conclusions can be drawn:

1. Daily maximum air temperature is slightly overestimated by the model, while minimum temperature is significantly overestimated. This overestimation is strongest for the inland area of Ioannina, where the bias for minimum temperature is $6^{\circ} \mathrm{C}$.

2. Surface wind speed is generally overestimated by the model. This can be considered as logical, taking into account the small-scale (lower than $2 \mathrm{~km}$, which is the spatial analysis of Grid 3) natural and artificial obstacles near the ground, not being simulated in the $2 \times 2 \mathrm{~km}$ model forecasts.

3. Precipitation prediction is generally satisfactory, as indicated by the categorical statistical tests for 24- and 6-h totals.

4. Verification of thunderstorm warnings for all sub-areas, using as ground-truth lightning data from ZEUS lightning detection system revealed the need for refinement of the corresponding warnings thresholds, in order to increase the probability of detection of thunderstorm activity.

5. The application of the warning system seems to work properly and the only issue that could be further examined is the definition of thresholds for precipitation amount.

The authors plan to continue the verification of the system for a longer period, introducing a larger observational dataset, since in 2009 a new network of 10 automatic weather stations has been installed in the area.

Acknowledgements. This work was supported by RISKMED project, Programme INTERREG IIIB/ARCHIMED.

Edited by: A. Mugnai

Reviewed by: two anonymous referees

\section{References}

Akylas, E., Kotroni, V., and Lagouvardos, K.: Sensitivity of high resolution operational weather forecasts to the choice of the planetary boundary layer scheme, Atmos. Res., 84, 49-57, 2007. 
Alpert, P., Neeman, B. U., and Shay-El, Y.: Intermonthly variability of cyclone tracks in the Mediterranean, J. Climate, 3, 1474-1478, 1990.

Bartzokas, A. and Houssos, E. E.: Extreme temperature events in NW Greece, in: Proceedings of the 10th International Conference on Harmonisation within Atmospheric Dispersion Modelling for Regulatory Purposes, Sissi (Malia), Crete, 556-560, 17-20 October 2005.

Bartzokas, A., Azzopardi, J., Bertotti, L., Buzzi, A., Cavaleri, L., Conte, D., Davolio, S., Dietrich, S., Drago, A., Drofa, O., Gkikas, A., Kotroni, V., Lagouvardos, K., Lolis, C. J., Michaelides, S., Miglietta, M., Mugnai, A., Music, S., Nikolaides, K., Porcù, F., Savvidou, K., and Tsirogianni, M.I.: The RISKMED project: Philosophy, methods and results, Nat. Hazards Earth Syst. Sci., in review, 2010.

Dalezios, N. R. and Papamanolis, N. K.: Objective assessment of instability indices for operational hail forecasting in Greece, Meteorol. Atmos. Phys., 45, 87-100, 1991.

Dudhia, J.: A non-hydrostatic version of the Penn State/NCAR mesoscale model: validation tests and simulation of an Atlantic cyclone and cold front, Mon. Weather Rev., 121, 1493-1513, 1993.

Hong, S. Y. and Pan, H. L.: Nonlocal boundary layer vertical diffusion in a medium-range forecast model, Mon. Weather Rev., 124, 2322-2339, 1996.

Houssos, E. E. and Bartzokas, A.: Extreme precipitation events in NW Greece, Adv. Geosci., 7, 91-96, 2006, http://www.adv-geosci.net/7/91/2006/.

Kain, J. S. and Fritsch, J. M.: Convective parameterization for mesoscale models: the Kain-Fritsch scheme. The Representation of Cumulus in numerical models, American Meteorological Society, Meteor Mon., No 46, 165-177, 1993.

Katsoulis, V. D. and Pappas, C.: Study of the application of the gamma distribution to the frequency distribution of precipitation, in: Proceedings of the 5th Hellenic Conference in Meteorology, Climatology and Atmospheric Physics, University of Thessaloniki, 277-284, 28-30 September 2000.

Koletsis, I., Lagouvardos, K., Kotroni, V., and Bartzokas, A.: Numerical study of a downslope windstorm in Northwestern Greece, Atmos. Res., 94, 178-193, 2009.
Kotroni, V., Kallos, G., and Lagouvardos, K.: Convergence zones over the Greek peninsula and associated thunderstorm activity, Q. J. Roy. Meteor. Soc., 123, 1961-1984, 1997.

Kotroni, V. and Lagouvardos, K.: Precipitation forecast skill of different convective parameterization and microphysical schemes: application for the cold season over Greece, Geophys. Res. Lett., 108, 1977-1980, 2001.

Kotroni, V. and Lagouvardos, K.: Evaluation of MM5 highresolution real-time forecasts over the urban area of Athens, Greece, J. Appl. Meteorol., 43, 1666-1678, 2004.

Kotroni, V. and Lagouvardos, K.: Lightning occurrence in relation with elevation, terrain slope and vegetation cover over the Mediterranean. J. Geophys. Res. Atmos., 113, D21118, doi:10.1029/2008JD010605, 2008.

Lagouvardos, K., Kotroni, V., Betz, H.-D., and Schmidt, K.: A comparison of lightning data provided by ZEUS and LINET networks over Western Europe, Nat. Hazards Earth Syst. Sci., 9, 1713-1717, 2009, http://www.nat-hazards-earth-syst-sci.net/9/1713/2009/.

Lolis, C. J., Metaxas, D. A., and Bartzokas, A.: On the intra-annual variability of atmospheric circulation in the Mediterranean region, Int. J. Climatol., 28, 1339-1355, 2008.

Maheras, P., Flocas, H. A., Patrikas, I., and Anagnostopoulou, C.: A 40 year objective climatology of surface cyclones in the Mediterranean region: spatial and temporal distribution, Int. J. Climatol., 21, 109-130, 2001.

Metaxas, D. A.: Evidence on the importance of diabatic heating as divergence factor in the Mediterranean, Arch. Meteorol. Geophys. Bioklimatol. A, 27, 69-80, 1978.

Schultz, P.: An explicit cloud Physics parametrization for operational numerical weather prediction, Mon. Weather Rev., 123, 3331-3343, 1995.

Trigo, I. F., Bigg, G. R., and Davies, T. D.: Climatology of cyclogenesis mechanisms in the Mediterranean, Mon. Weather Rev., 130, 549-569, 2002. 